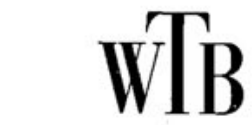

BAND 20

Wolfgang Fleischer

Die deutschen Personennamen

Geschichte, Bildung und Bedeutung

A K A D E M I E - V E R L A G - B E R L I N

1964 


\title{
Reihe SPRACHWISSENSCHAFT
}

\author{
Herausgegeben von: Prof. Dr. K. Ammer, Halle (Saale) \\ Dr. E. Arndt, Berlin \\ Dr. G. Feudel, Berlin \\ Prof. Dr. R. Große, Leipzig \\ Prof. Dr. G. F. Meier, Berlin \\ Dr. W. Neumann, Berlin
}

Erschienen im Akademie -Verlag GmbH,

Berlin W 8, Leipziger Straße 3-4

Copyright 1964 by Akademie-Verlag Gmbh

Lizenznummer: $202 \cdot 100 / 80 / 64$

Gesamtherstellung: IV/2/14 - VEB Werkdruck Gräfenhainichen $\cdot 218 \mathrm{C}$

Bestellnummer: 7020

Preis: DM 12,50 